\title{
Specific and Quantitative Detection of Albumin in Biological Fluids by Tetrazolate-Functionalized Water-Soluble AIEgens
}

Yujie Tu ${ }^{\dagger \ddagger \S}$, Yeqing $\mathrm{Yu}^{\ddagger}$, Zhibiao Zhou ${ }^{\dagger}$, Sheng Xie ${ }^{* \dagger \ddagger}$, Bicheng Yao $^{\ddagger \S}$, Shujuan Guan ${ }^{\perp}$, Bo Situ $^{\perp}$, Yong Liu ${ }^{\ddagger \S}$, Ryan T. K. Kwok ${ }^{\ddagger}$, Jacky W. Y. Lam ${ }^{\ddagger \S}$, Sijie Chen $\nabla$, Xuhui Huang ${ }^{\ddagger}$, Zebing Zeng ${ }^{\dagger}$, Ben Zhong Tang ${ }^{* \star \star \S} \|$

$\uparrow$ State Key Laboratory of Chemo/Biosensing and Chemometrics, College of Chemistry and Chemical Engineering, Hunan University, Changsha 410082, China;

$\ddagger$ Department of Chemistry, The Hong Kong University of Science and Technology, Clear Water Bay, Kowloon, Hong Kong, China;

$\S$ Hong Kong Branch of Chinese National Engineering Research Center for Tissue Restoration and Reconstruction, The Hong Kong University of Science and Technology, Clear Water Bay, Kowloon, Hong Kong, China;

|| State Key Laboratory of Luminescent Materials and Devices, Center for Aggregation-Induced Emission, (Guangzhou International Campus,) South China University of Technology, Guangzhou 510640, China;

$\perp$ Department of Laboratory Medicine, Nanfang Hospital, Southern Medical University, Guangzhou, 510515 China;

$\nabla$ Ming Wai Lau Center for Reparative Medicine, Karolinska Institutet, Hong Kong, China.

\section{Corresponding Author}

*shengxie@hnu.edu.cn

*tangbenz@ust.hk 

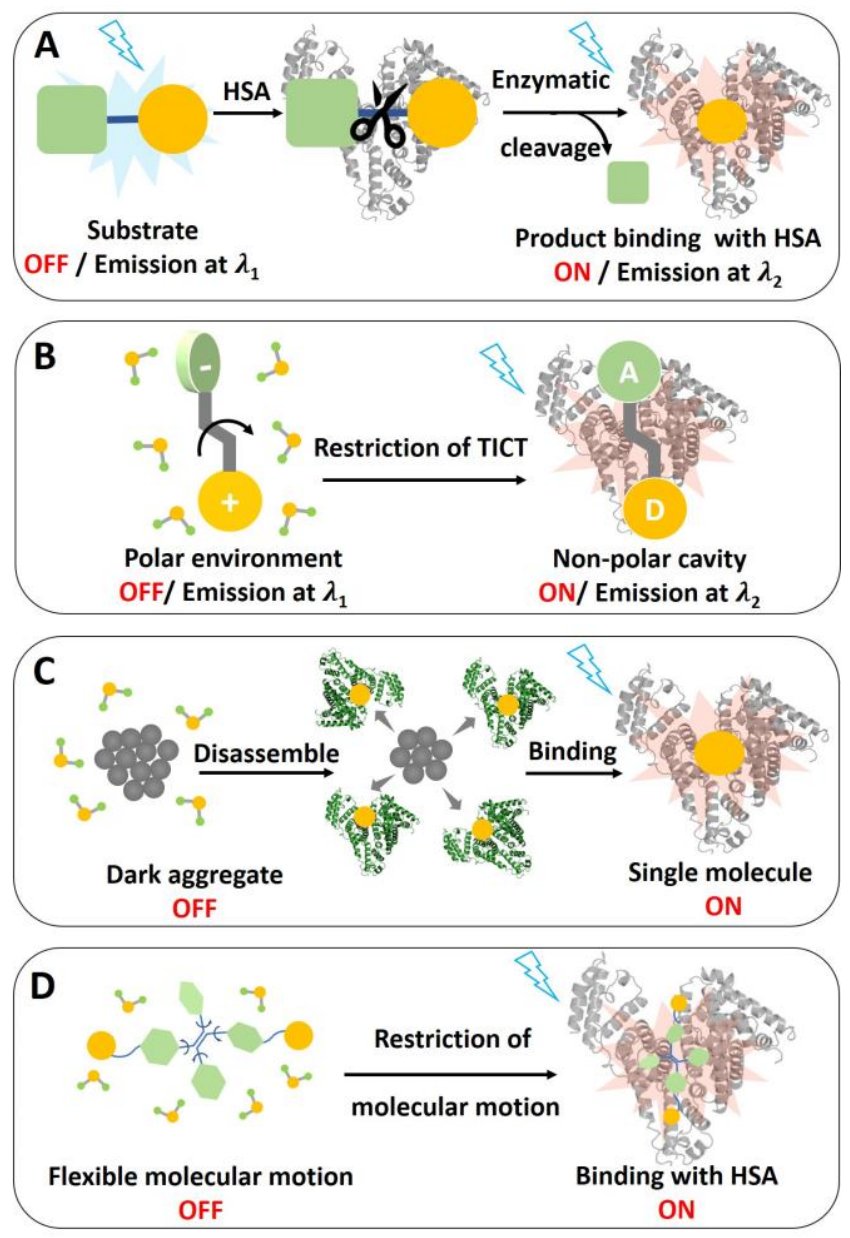

Figure S1. Summary of working mechanisms for designing turn-on fluorescent probes in HSA detection. (A) aromatic amides/esters which can undergo enzymatic hydrolysis in the presence of albumins due to albumin's pseudo-esterase activity. (B) push-pull probes by modulating the twisted intramolecular charge transfer (TICT) process between the non-polar albumin binding sites and polar aqueous environment. (C) caged dyes or dark aggregates which can disassemble, disperse into albumin cavities and turn on the emission. (D) water-soluble aggregation-induced emission luminogens which are not emissive when dissolved while can be lighted up after binding with HSA due to the restriction of molecular motion mechanism.


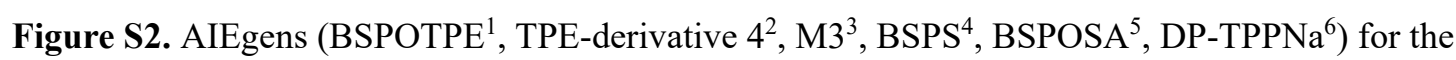
albumin detection. 
Table S1. Summary of performances of reported fluorogenic albumin probes.

\begin{tabular}{|c|c|c|c|c|c|c|}
\hline Name & Structure & $\begin{array}{c}\lambda_{\mathrm{ex}} / \lambda_{\mathrm{em}} \\
(\mathrm{nm})\end{array}$ & $\begin{array}{l}\text { LOD } \\
\text { (nM) }\end{array}$ & $\begin{array}{c}\mathbf{K}_{\mathbf{D}} \\
(\boldsymbol{\mu M})\end{array}$ & $\begin{array}{c}\text { LDR } \\
(\mathrm{mg} / \mathrm{L})\end{array}$ & Ref. \\
\hline BSPOTPE & & $350 / 460$ & 1 & - & $0.665 \sim 6.65$ & [1] \\
\hline BSPS & & $355 / 508$ & 91.9 & - & $6.11 \sim 100$ & [4] \\
\hline $\begin{array}{c}\text { DP- } \\
\text { TPPNa }\end{array}$ & & $310 / 443$ & 25.26 & - & $1.68 \sim 100$ & [6] \\
\hline DB-15C5 & & $360 / 500$ & 1.7 & 8.87 & $0.112 \sim 80$ & [7] \\
\hline AB580 & & $590 / 616$ & 6.02 & 0.077 & $2 \sim 200$ & [8] \\
\hline HMM & & $482 / 562$ & 0.75 & 2.7 & $\sim 100$ & [9] \\
\hline ACDM & & $560 / 612$ & 37.6 & 10.87 & $2.5 \sim 300$ & [10] \\
\hline SA4 & & $536 / 685$ & 0.00115 & 5.08 & $3.7 \sim 853.7$ & [11] \\
\hline AL-1 & & $440 / 490$ & 6.02 & 1.77 & $0.4 \sim 67$ & [12] \\
\hline DMAR & & $460 / 547$ & 1.95 & 3.22 & $0.13 \sim 33$ & [13] \\
\hline HCAB & & $426 / 524$ & 28.7 & 1.3 & $1.91 \sim 100$ & [14] \\
\hline NIR-HSA & & $580 / 680$ & 26.2 & - & $1.73 \sim 665$ & [15] \\
\hline BDC-9 & & $460 / 575$ & 4.51 & 12.7 & $0.37 \sim 31$ & [16] \\
\hline G13 & & $522 / 544$ & - & 1.25 & $\sim 150$ & [17] \\
\hline
\end{tabular}

LOD: Limit of detection; $\mathrm{K}_{\mathrm{D}}$ : dissociation constant; LDR: linear dynamic range. 

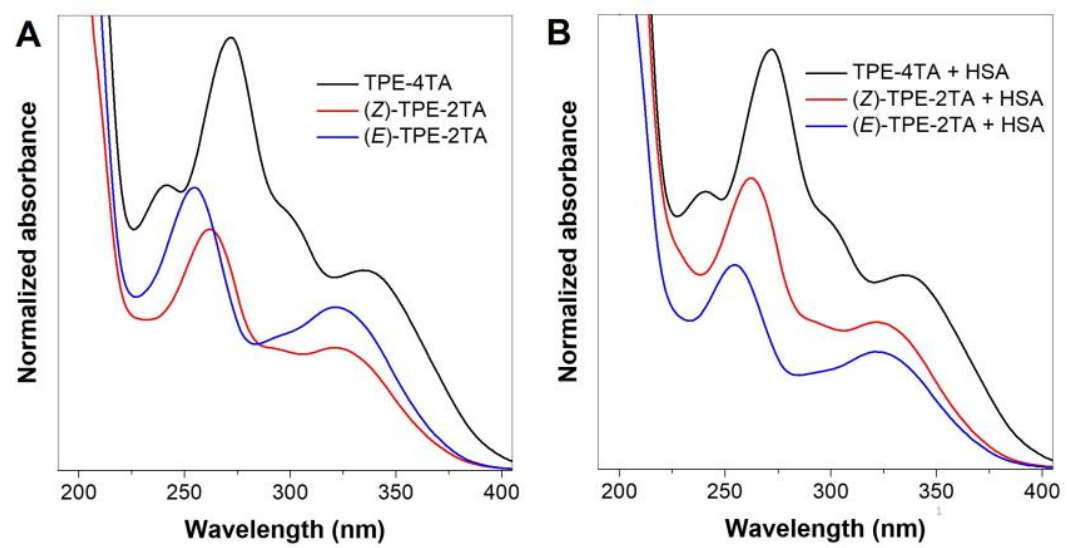

Figure S3 UV-vis absorption spectra of AIEgens in the absence (A) and presence (B) of HSA
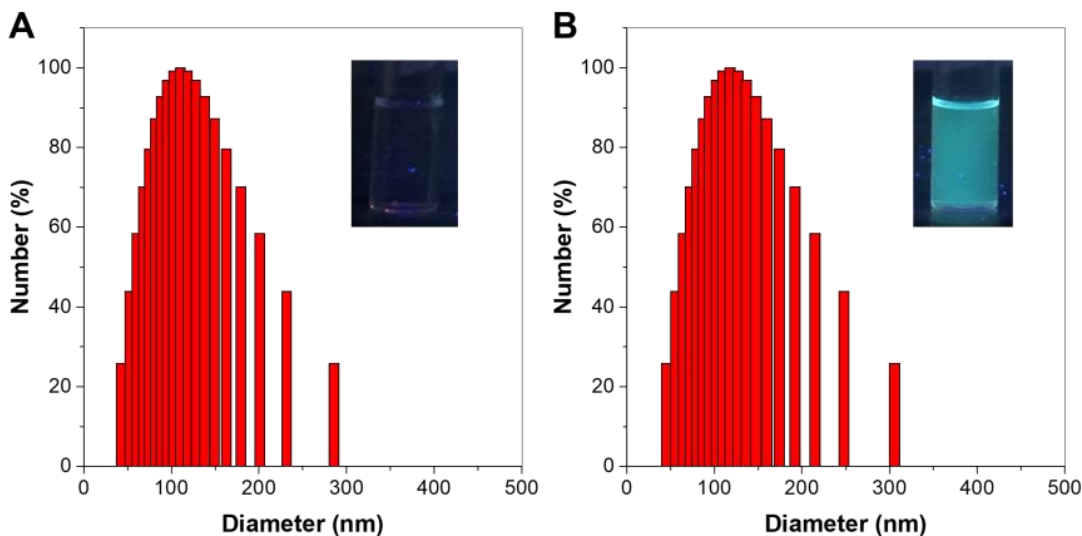

Figure S4. Dynamic light scattering analysis of (A) HSA (50mg/L) (B) HSA (50mg/L) in addition of TPE-4TA $(10 \mu \mathrm{M})$. Inset: Photos of target solution taken under UV light.


Figure S5. (A) Excitation and emission spectra of three AIEgen-HSA complexes. (B) Linear response of TPE-4TA at $5 \mu \mathrm{M}$ and $125 \mu \mathrm{M}$ towards human serum albumin. $\lambda_{\mathrm{ex}}=370 \mathrm{~nm}$. $I_{0}$ is the fluorescence intensity at $[\mathrm{HSA}]=0 \mathrm{mg} / \mathrm{L}$. 

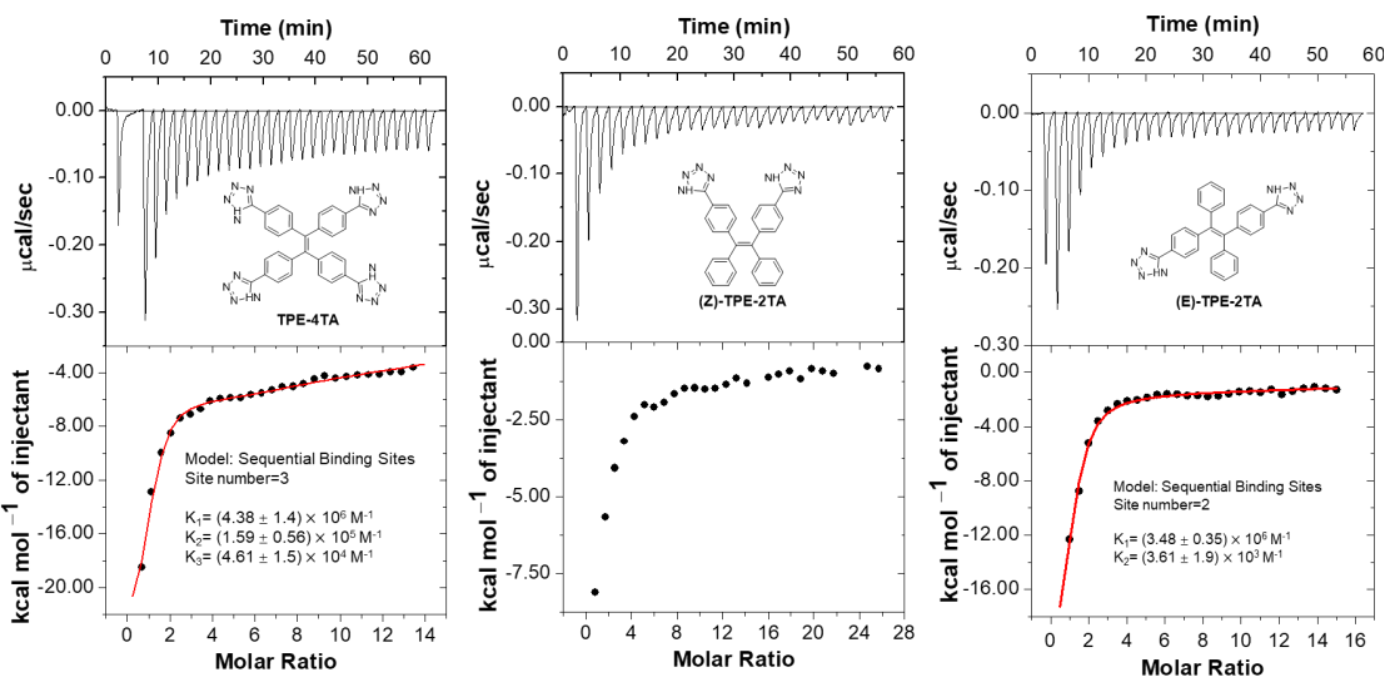

Figure S6. Binding isotherms for the interaction between AIEgens ligands and HSA protein. The top panels show the calorimetric traces recorded by titrating HSA solution in a cell with AIEgens solutions in the syringe at $25^{\circ} \mathrm{C}$. The bottom panels show the integrated heat of each injections and the fitting lines with sequential binding sites model. [AIEgens] $=0.07 \mathrm{mM}$.

Table S2. Docking energies of TPE-4TA in three binding sites obtained by all-atom MD simulation.

\begin{tabular}{ccccc}
\hline Sites & $\begin{array}{c}\text { Electrostatic } \\
\text { energy }(\mathrm{kJ} / \mathrm{mol})\end{array}$ & $\begin{array}{c}\text { Polar solvation } \\
\text { energy }(\mathrm{kJ} / \mathrm{mol})\end{array}$ & $\begin{array}{c}\text { van der Waal } \\
\text { energy }(\mathrm{kJ} / \mathrm{mol})\end{array}$ & $\begin{array}{c}\text { Binding energy } \\
(\mathrm{kJ} / \mathrm{mol})\end{array}$ \\
\hline Cleft 1 & -50.516 & 64.923 & -201.477 & -207.695 \\
Cleft 2 & -159.624 & 202.034 & -213.640 & -197.062 \\
DIII & -341.260 & 515.419 & -192.627 & -38.615 \\
\hline
\end{tabular}

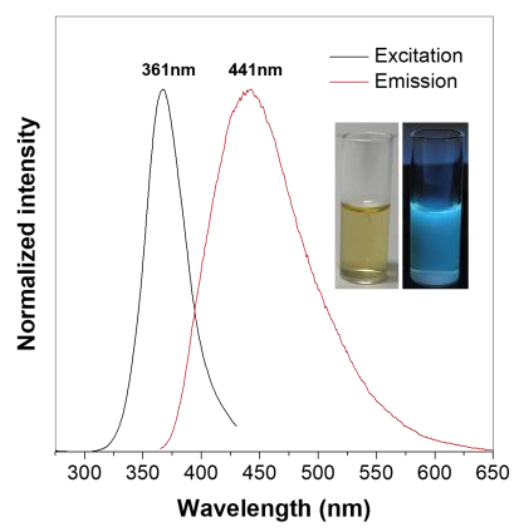

Figure S7. Fluorescence spectra of a urine sample showing auto-fluorescence. 
NMR Spectra:

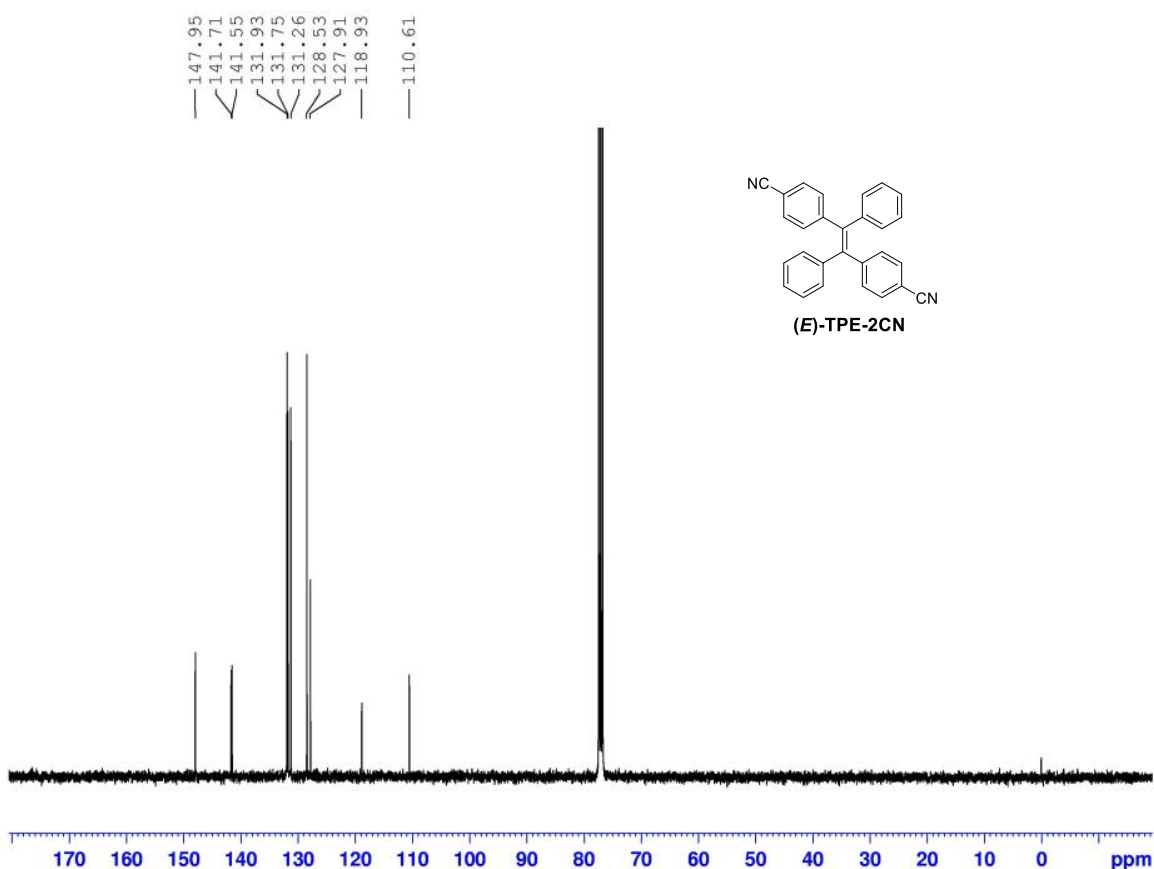

Figure S9. ${ }^{13} \mathrm{C}$ NMR spectrum of $(E)$-TPE-2CN in $\mathrm{CDCl}_{3}$.

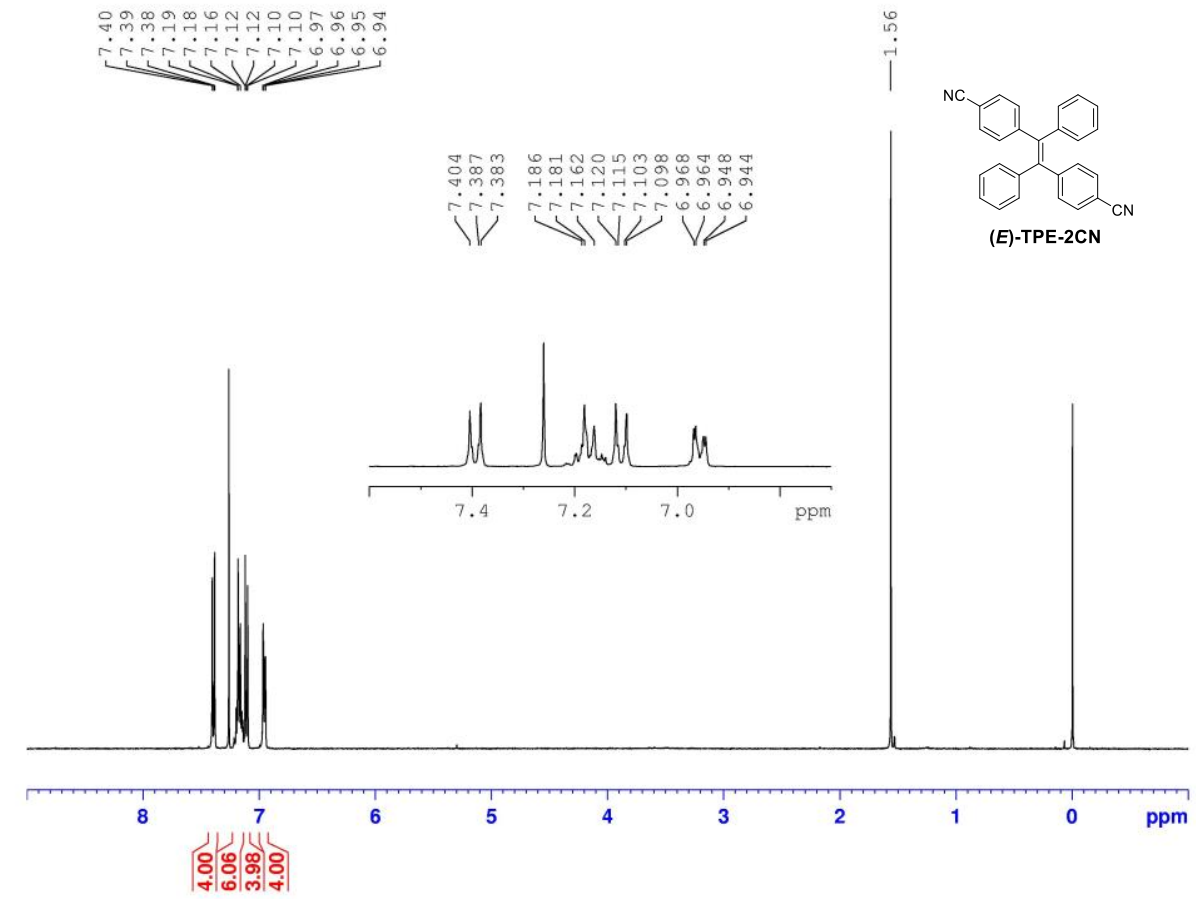

Figure S10. ${ }^{1} \mathrm{H}$ NMR spectrum of $(E)$-TPE- $2 \mathrm{CN}$ in $\mathrm{CDCl}_{3}$. 


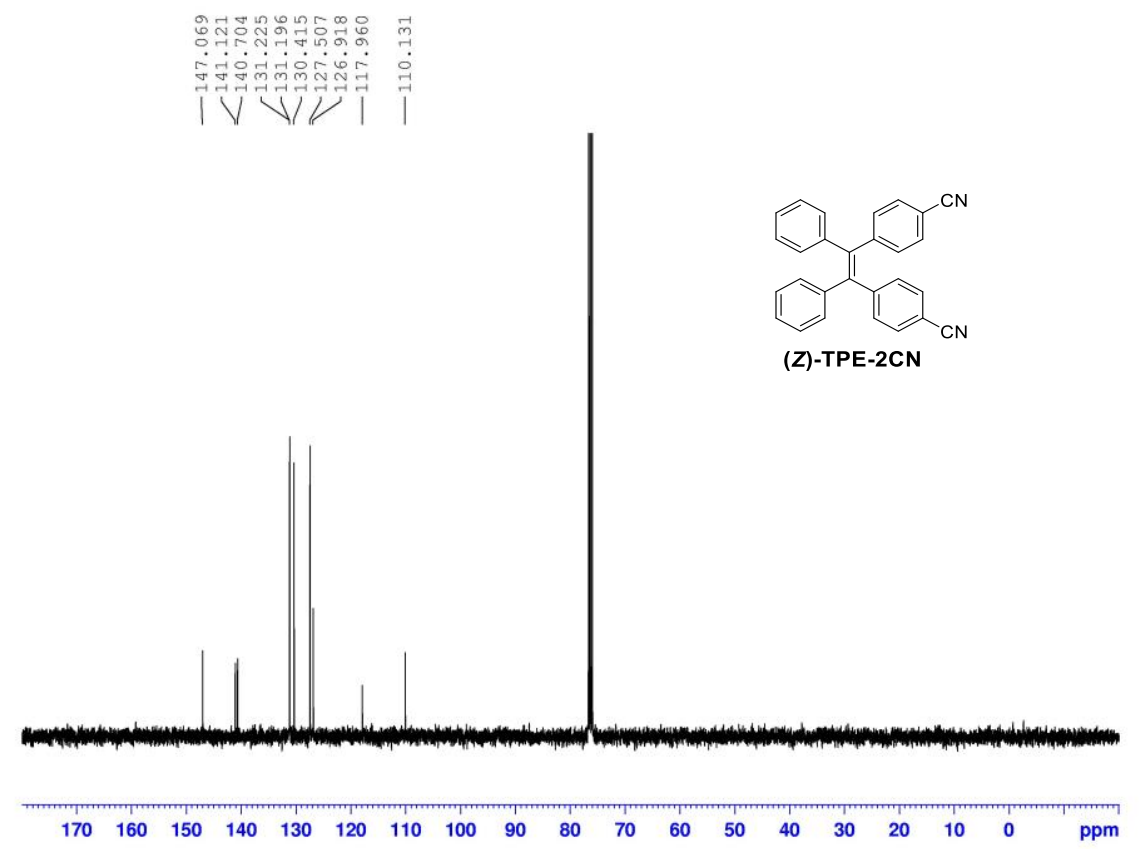

Figure S11. ${ }^{13} \mathrm{C}$ NMR spectrum of $(Z)-\mathrm{TPE}-2 \mathrm{CN}$ in $\mathrm{CDCl}_{3}$.
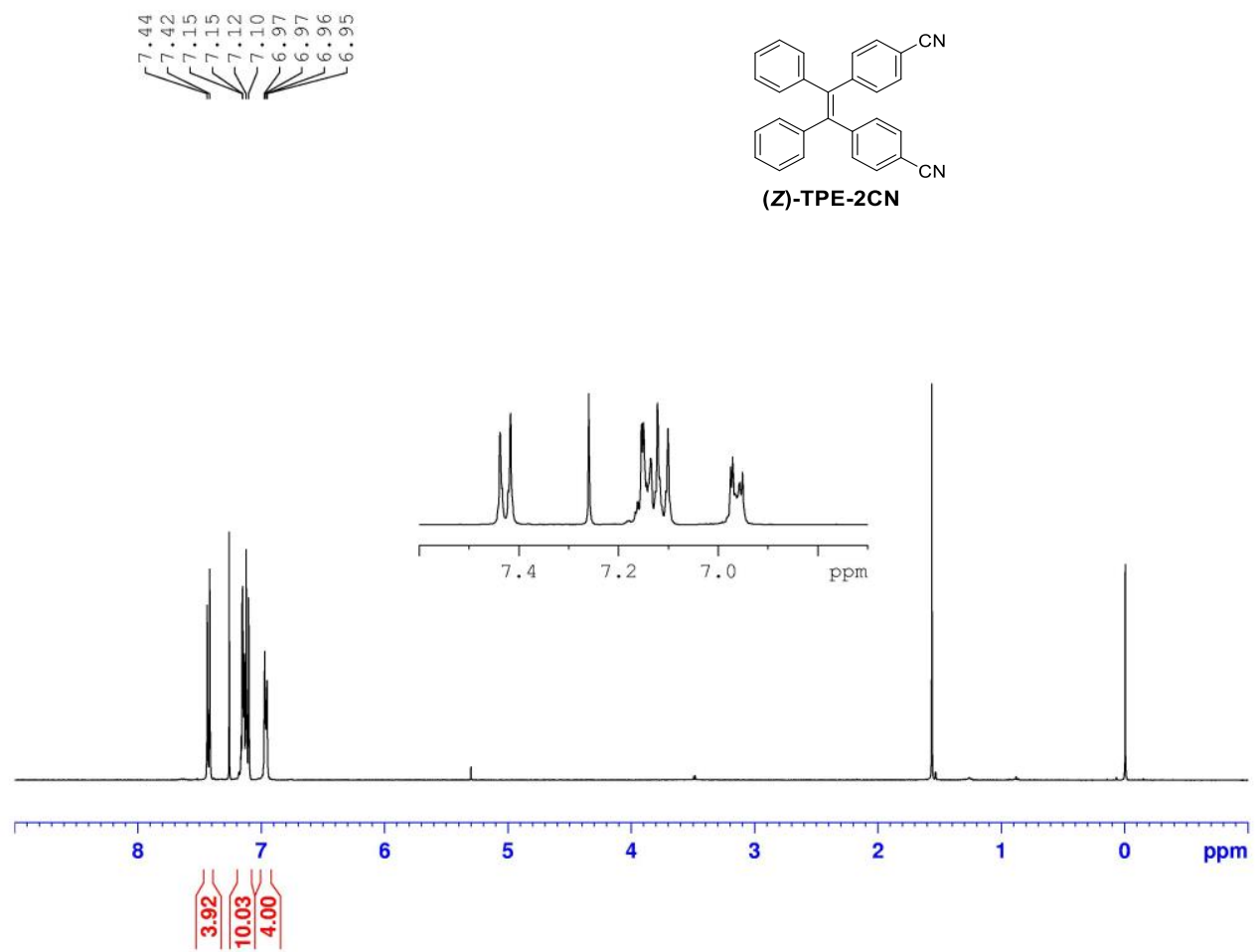

Figure S12. ${ }^{1} \mathrm{H}$ NMR spectrum of $(Z)-\mathrm{TPE}-2 \mathrm{CN}$ in $\mathrm{CDCl}_{3}$. 




Figure S13. ${ }^{13} \mathrm{C}$ NMR spectrum of $(E)$-TPE-2TAH in DMSO-d6.



Figure S14. ${ }^{1} \mathrm{H}$ NMR spectrum of $(E)$-TPE-2TAH in DMSO-d6. 


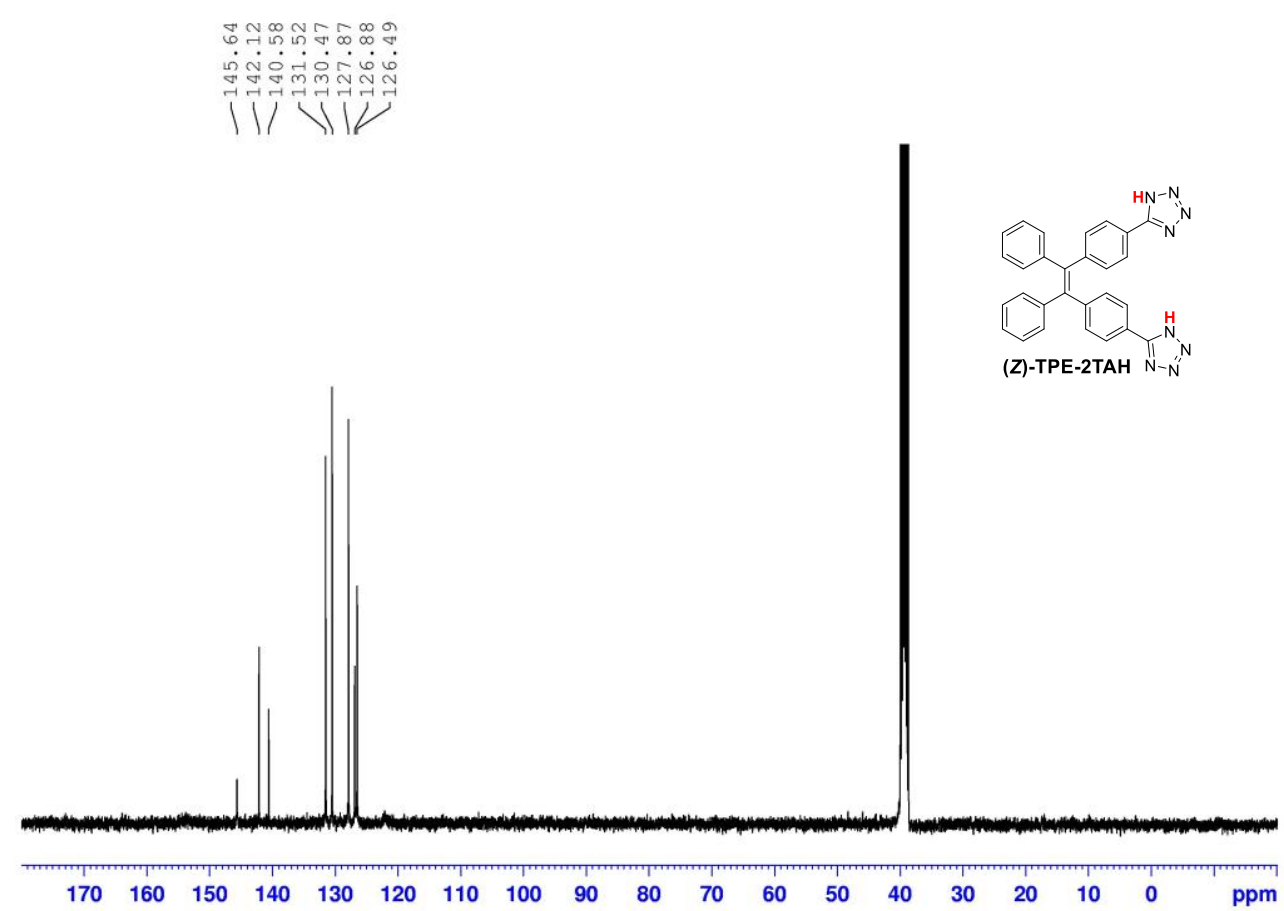

Figure S15. ${ }^{13} \mathrm{C}$ NMR spectrum of $(Z)$-TPE-2TAH in DMSO-d6.

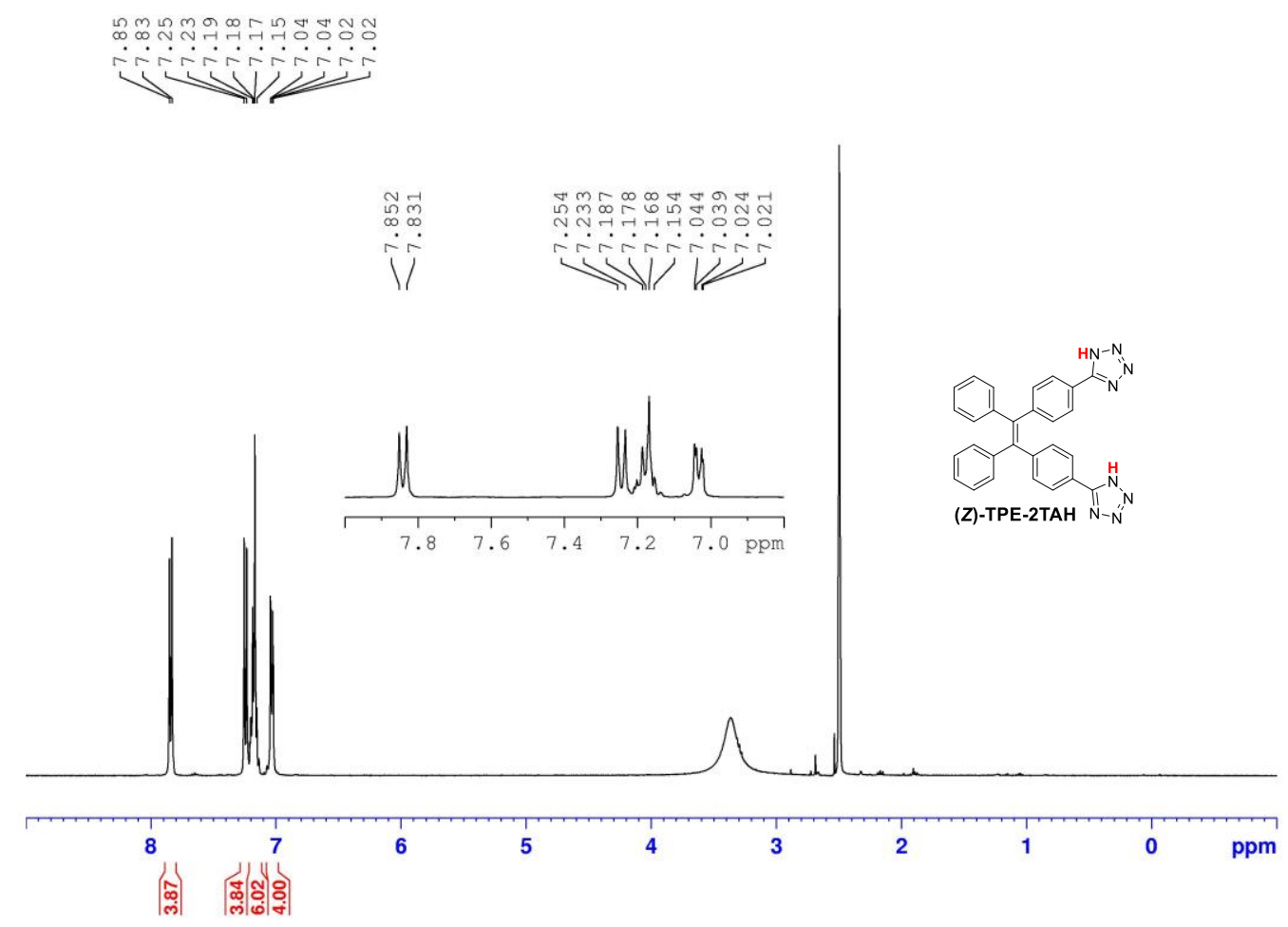

Figure S16. ${ }^{1} \mathrm{H}$ NMR spectrum of (Z)-TPE-2TAH in DMSO-d6.

\section{Mass Spectra:}






Figure S17. Mass spectrum of (Z)-TPE-2CN.

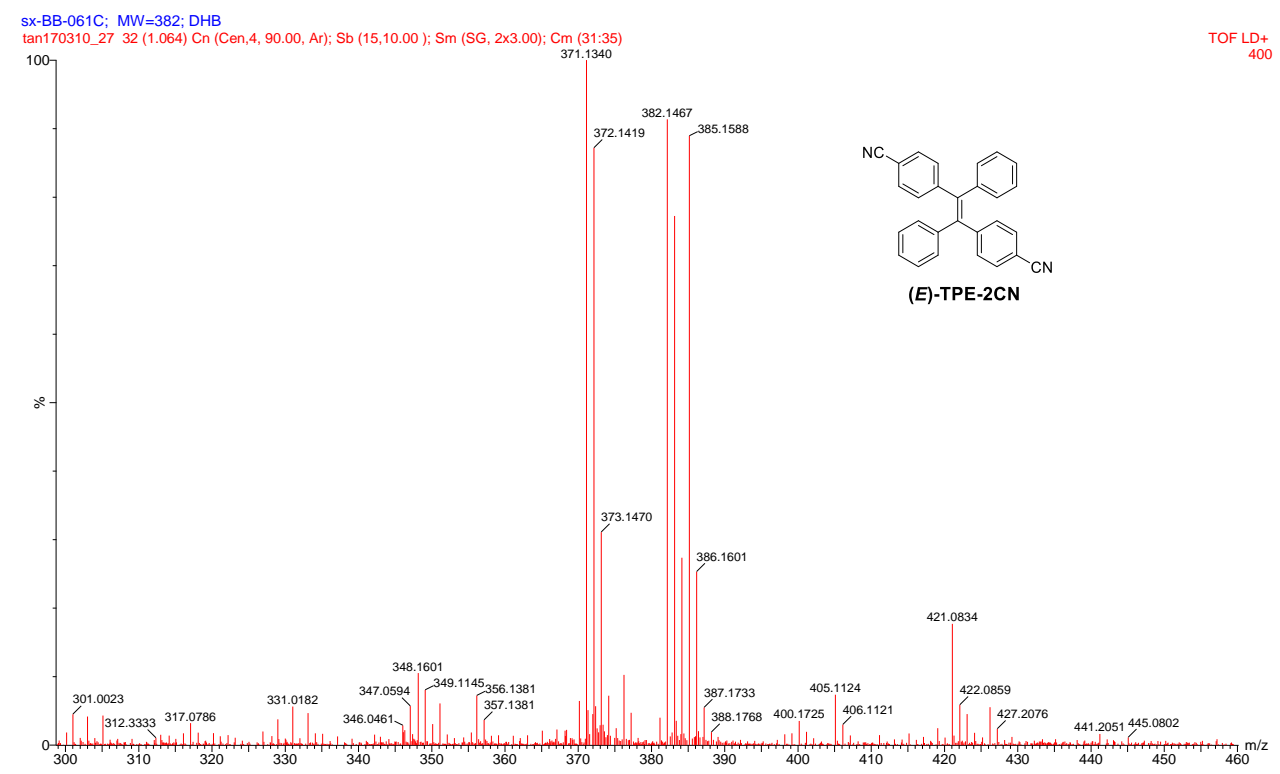

Figure S18. Mass spectrum of (E)-TPE-2CN. 


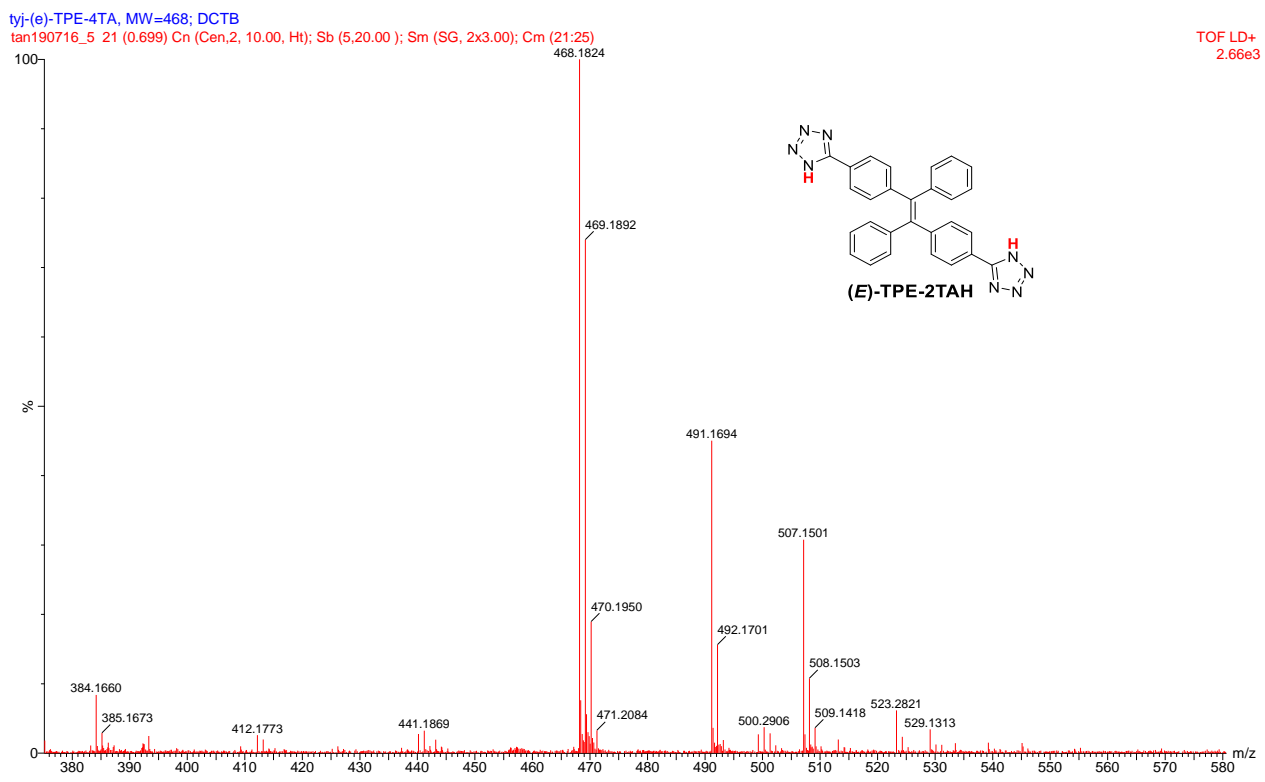

Figure S19. Mass spectrum of $(E)$-TPE-2TAH.

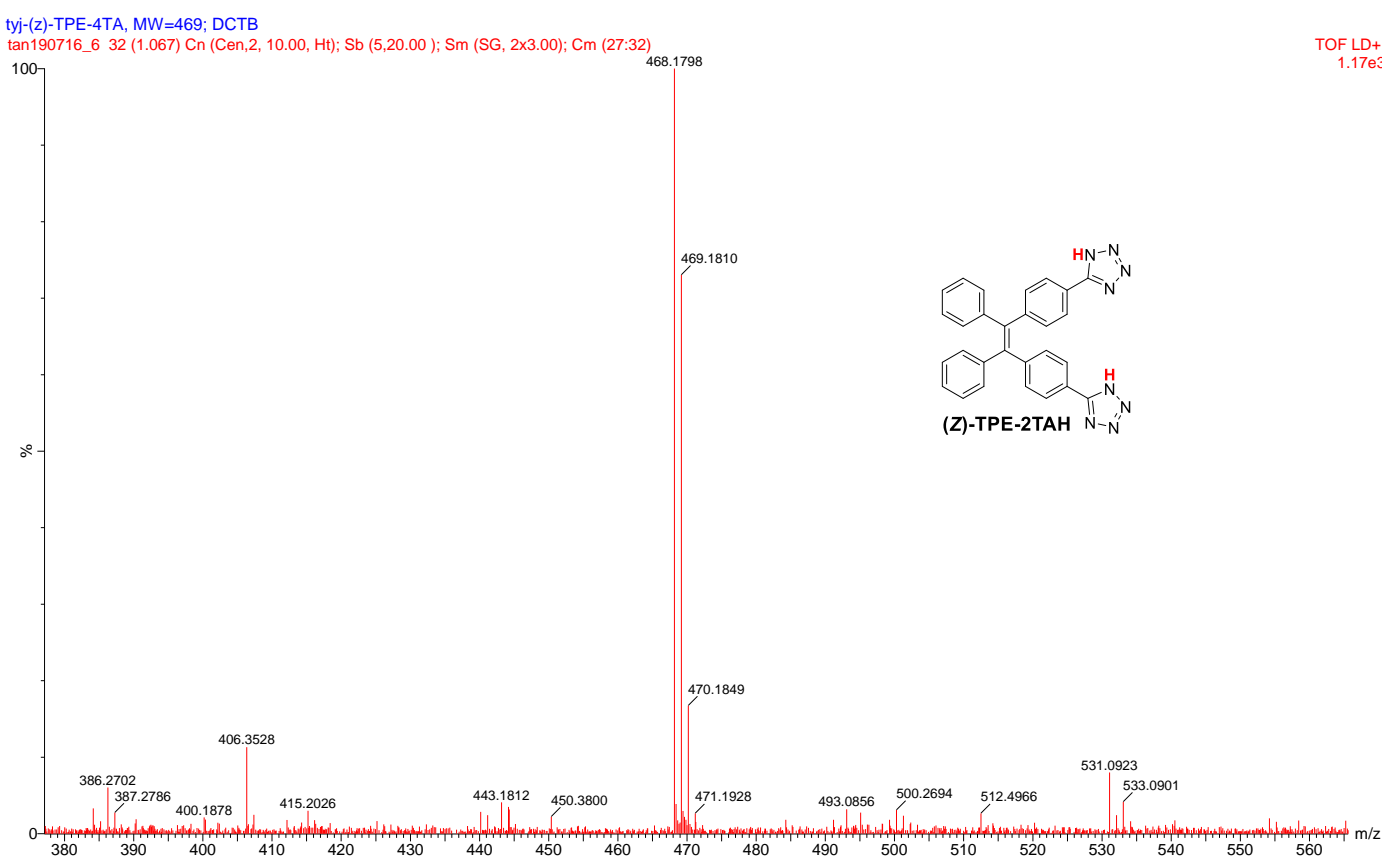

Figure S20. Mass spectrum of (Z)-TPE-2TAH.

\section{Reference}

(1) Hong, Y. N.; Feng, C.; Yu, Y.; Liu, J. Z.; Lam, J. W. Y.; Luo, K. Q.; Tang, B. Z. Quantitation, Visualization, and Monitoring of Conformational Transitions of Human Serum Albumin by a Tetraphenylethene Derivative with Aggregation-Induced Emission Characteristics. Anal. Chem. 2010, 82, 7035-7043. 
(2) Tong, H.; Hong, Y.; Dong, Y.; Haussler, M.; Lam, J. W.; Li, Z.; Guo, Z.; Guo, Z.; Tang, B. Z. Fluorescent "Light-up" Bioprobes Based on Tetraphenylethylene Derivatives with Aggregation-Induced Emission Characteristics. Chem. Commun. (Camb.). 2006, 35, 3705-3707.

(3) Tong, J.; Hu, T.; Qin, A.; Sun, J. Z.; Tang, B. Z. Deciphering the Binding Behaviours of Bsa Using Ionic Aie-Active Fluorescent Probes. Faraday Discuss. 2017, 196, 285-303.

(4) Li, J.; Wu, J.; Cui, F.; Zhao, X.; Li, Y.; Lin, Y.; Li, Y.; Hu, J.; Ju, Y. A Dual Functional Fluorescent Sensor for Human Serum Albumin and Chitosan. Sensors Actuators B: Chem. 2017, 243, 831-837.

(5) Wang, Z.; Ma, K.; Xu, B.; Li, X.; Tian, W. A Highly Sensitive “Turn-on” Fluorescent Probe for Bovine Serum Albumin Protein Detection and Quantification Based on Aie-Active Distyrylanthracene Derivative. Sci. China. Chem. 2013, 56, 1234-1238.

(6) Li, W.; Chen, D.; Wang, H.; Luo, S.; Dong, L.; Zhang, Y.; Shi, J.; Tong, B.; Dong, Y. Quantitation of Albumin in Serum Using "Turn-on" Fluorescent Probe with Aggregation-Enhanced Emission Characteristics. ACS Appl. Mater. Interfaces. 2015, 7, 26094-26100.

(7) Shen, P.; Hua, J.; Jin, H.; Du, J.; Liu, C.; Yang, W.; Gao, Q.; Luo, H.; Liu, Y.; Yang, C. Recognition and Quantification of Hsa: A Fluorescence Probe across A-Helices of Site I and Site Ii. Sensors Actuators B: Chem. 2017, 247, 587-594.

(8) Kessler, M. A.; Meinitzer, A.; Petek, W.; Wolfbeis, O. S. Microalbuminuria and Borderline-Increase Albumin Excretion Determined with a Centrifugal Analyzer and the Albumin Blue 580 Fluorescence Assay. Clin. Chem. 1997, 43, 996-1002.

(9) Wang, Y.-R.; Feng, L.; Xu, L.; Hou, J.; Jin, Q.; Zhou, N.; Lin, Y.; Cui, J.-N.; Ge, G.-B. An Ultrasensitive and Conformation Sensitive Fluorescent Probe for Sensing Human Albumin in Complex Biological Samples. Sensors Actuators B: Chem. 2017, 245, 923-931.

(10) Wang, Y. R.; Feng, L.; Xu, L.; Li, Y.; Wang, D. D.; Hou, J.; Zhou, K.; Jin, Q.; Ge, G. B.; Cui, J. N.; Yang, L. A Rapid-Response Fluorescent Probe for the Sensitive and Selective Detection of Human Albumin in Plasma and Cell Culture Supernatants. Chem. Commun. (Camb.). 2016, 52, 6064-6067.

(11) Zhu, T.; Du, J.; Cao, W.; Fan, J.; Peng, X. Microenvironment-Sensitive Fluorescent Dyes for Recognition of Serum Albumin in Urine and Imaging in Living Cells. Ind. Eng. Chem. Res. 2016, 55, 527-533.

(12) Wu, Y. Y.; Yu, W. T.; Hou, T. C.; Liu, T. K.; Huang, C. L.; Chen, I. C.; Tan, K. T. A Selective and Sensitive Fluorescent Albumin Probe for the Determination of Urinary Albumin. Chem. Commun. (Camb.). 2014, 50, 11507-11510.

(13) Du, J.; Zhu, T.; Gu, Q.; Cao, W.; Fan, J.; Peng, X. Fabrication of Artificial Fluorescent Protein Probe for Hsa Recognition and Relay Sensing Ag + by Functional Microenvironment-Sensitive Fluorescent Dye. Sensors Actuators B: Chem. 2018, 263, 661-667.

(14) Li, P.; Wang, Y.; Zhang, S.; Xu, L.; Wang, G.; Cui, J. An Ultrasensitive Rapid-Response Fluorescent Probe for Highly Selective Detection of Hsa. Tetrahedron Lett. 2018, 59, 1390-1393.

(15) Li, H.; Yao, Q.; Fan, J.; Du, J.; Wang, J.; Peng, X. An Nir Fluorescent Probe of Uric Hsa for Renal Diseases Warning. Dyes and Pigments. 2016, 133, 79-85.

(16) Er, J. C.; Tang, M. K.; Chia, C. G.; Liew, H.; Vendrell, M.; Chang, Y.-T. Megastokes BodipyTriazoles as Environmentally Sensitive Turn-on Fluorescent Dyes. Chem. Sci.. 2013, 4, 2168.

(17) Ahn, Y. H.; Lee, J. S.; Chang, Y. T. Selective Human Serum Albumin Sensor from the Screening of a Fluorescent Rosamine Library. J. Comb. Chem. 2008, 10, 376-380. 